\title{
Correlations Between Prognosis and Regional Biomarker Profiles in Head and Neck Squamous Cell Carcinomas
}

\author{
Gabriella Szentkúti • Kornél Dános • Diána Brauswetter • \\ Gergő Kiszner • Tibor Krenács • László Csákó • \\ Gábor Répássy • László Tamás
}

Received: 11 February 2014 / Accepted: 6 November 2014 / Published online: 31 December 2014

(C) Arányi Lajos Foundation 2014

\begin{abstract}
Head and neck squamous cell carcinomas (HNSC C) show diverse clinicopathological features and are mostly linked with poor outcome. In this study, we tested if the expression of tumor growth, cell cycle and basement membrane anchorage related biomarkers allow prognostic and clinicopathological stratification of HNSCC. Archived HNSCC samples from 226 patients included into tissue microarrays (TMA) were tested using immunohistochemistry. Histopathological evaluation and the analysis of immunostaining for EGFR, Ki67, p53, p16 ${ }^{\text {ink4 }}$ and Collagen XVII proteins were carried out in digital whole slides. Statistical evaluation was carried out using Pearson's Chi-square test and Kaplan-Meier survival analysis. In the tested cohort, hypopharyngeal cancers had the least favorable, and glottic cancers had the most favorable prognosis. High Ki67 positive tumor cell fractions were associated with significantly worse prognosis and elevated rate of lymph node metastasis. Both Ki67 and EGFR expression correlated significantly with the tumor localization. Ki67 index was the highest in the hypopharyngeal region and it proved to be the lowest in the
\end{abstract}

\section{G. Szentkúti $(\bowtie) \cdot$ L. Csákó}

Department of Oto-Rhino-Laryngology, Jahn Ferenc South-Pest

Hospital, 1st Köves Street, 1204 Budapest, Hungary

e-mail: g.szentkuti@gmail.com

K. Dános · G. Répássy • L. Tamás

Department of Oto-Rhino-Laryngology, Head-Neck Surgery,

Semmelweis University, Budapest, Hungary

D. Brauswetter

MTA-SE Pathobiochemistry Research Group, Budapest, Hungary

G. Kiszner • T. Krenács

1st Department of Pathology and Experimental Cancer Research,

Semmelweis University, Budapest, Hungary

T. Krenács

MTA-SE Tumor Progression Research Group, Budapest, Hungary glottic region. EGFR expression was the highest in the oral cavity and the lowest in the glottic region. The survival rate of patients with $\mathrm{p} 16^{\text {ink } 4}$-negative cancer was significantly lower than of those with $16^{\text {ink } 4}$-positive disease. A significant inverse correlation was found between histological grade and the prognosis of HNSCC. Our data support that elevated Ki67 positive proliferating cell fractions contribute to the unfavorable prognosis of hypopharyngeal cancers, while glottic cancers have the most favorable prognosis because of the lowest Ki67 expression rate.

Keywords Head and neck cancer · Biomarker · Prognostic factor $\cdot$ Ki67

\section{Introduction}

Every year, about half a million cases of new head and neck cancers are diagnosed worldwide with the vast majority of them are known to be squamous cell carcinomas [1]. Since head and neck squamous cell carcinomas (HNSCC) include a wide range of carcinomas into the same histopathological entity, members of this group may show variable clinicopathological features. The vast majority of HNSCC patients present with advanced diseases [2]. Stage III-IVb diseases usually require combination therapy (e.g. induction chemotherapy followed by chemoradiation), while biological therapy is reserved for metastatic and/or recurrent head and neck cancers [3]. The current biological- (cetuximab) and chemotherapeutic regimens (platinum based agents, 5-fluorouracil, taxanes) are rather toxic, and only a portion of the treated tumors show remission.

In the daily clinical practice, the TNM classification is used for selecting the most suitable therapeutic option. Among clinical parameters, age does not affect survival [4]. However, the prognostic role of histological grade is not well established 
in head and neck carcinomas [5]. The clinical outcome of HNSCC can differ according to anatomical localization. Glottic malignancies show the best and hypopharyngeal cancers the worst prognosis [2].

The fact that the mean survival of HNSCC patients is considerably poor with only $\sim 50 \%$ of 5 -year overall survival [2], urges investigations for finding novel prognostic markers and predictive markers that may support therapeutic decisions.

Previously identified biomarkers can help to predict prognosis of HNSCCs, however their clinical application is limited, currently, there is no evidence-based recommendation for altering the treatment of patients with HNSCCs on the basis of the expression of certain biomarkers [6].

Human Papillomavirus (HPV) has been recently raised as a driver of HNSCC development [7] suggesting that more than a half of tonsillar cancers are related to HPV [7]. This subset of HNSCC, however, showed better prognosis than cancers caused by tobacco and alcohol consumption [8]. The gold standard for evaluating HPV status is the detection of HPV E6/7 mRNA expression. However, it has been published that detecting tumor p16-expression by immunohistochemistry can be a surrogate marker with $100 \%$ sensitivity and $80 \%$ specificity [9]. The growth factor receptor EGFR is known to be overexpressed in 80-90\% of HNSCCs, and to be associated with poor survival, nevertheless it cannot be used as a predictor of response rate to cetuximab therapy [10].

By studying the expression of type I epidermal growth factor receptor (EGFR), the hemidesomosal adhesion molecule collagen XVII and the cell replication related proteins $\mathrm{p} 53, \mathrm{p} 16^{\mathrm{ink} 4}$, Ki67, we have earlier provided evidence on the differential biomarker expression in HNSCC according to anatomical localization [11]. In this study, we correlated the expression of these biomarkers with further clinicopathological features including disease prognosis in a larger HNSCC patient cohort.

\section{Materials and Methods}

Patients

HNSCC samples from 226 patients (177 men, 49 women; mean age: 58 years [36-89]) enrolled in this study were collected from the archives of Jahn Ferenc South-Pest Hospital, Budapest, Hungary between 2000 and 2008. Patients with rare cancer types (e.g. salivary gland tumors, nasopharyngeal carcinoma, sinonasal tumors and sarcomas) were excluded from the analysis because of their special clinical and morphological characteristics. The tested lesions included cancers of the oral cavity - 12 cases (body of tongue, floor of mouth); oropharynx -69 cases (18 palatine tonsil, 12 base of tongue, 5 tonsilo-lingual, 3 tonsillar fossa, 8 soft palate, 23 other part of oropharynx); hypopharynx - 43 cases; larynx - 102 cases (42 supraglottic, 43 glottic, 17 transglottic) (Table 1.).

Tissue Microarray (TMA) and Immunohistochemistry

Using the computer controlled TMA Master (3DHISTECH Kft., Budapest, Hungary), we created 8 TMA blocks containing duplicate cores of $2 \mathrm{~mm}$ diameter from formalin-fixed, paraffin-embedded tumor samples of the 226 HNSCC patients. Seven blocks contained 70 samples each and one contained 20 samples making up 510 cores for each staining.

Immunohistochemistry was performed in $4 \mu \mathrm{m}$ thick serial TMA sections following routine dewaxing, rehydration and blocking of endogeneous peroxidase activity using $3 \%$ hydrogene peroxide in ethanol for $15 \mathrm{~min}$. For antigen retrieval, the samples were boiled in Tris-EDTA buffer (pH: 9.0) for $25 \mathrm{~min}$. For immunodetection, the NovoLink-peroxidase polymer kit (Leica-NovoCastra, Newcastly-Upon Tyne, UK) was used. Immunostaining included the following sequential incubation steps using: $5 \%$ BSA in $0.1 \mathrm{M}$ Tris-buffered saline pH 7.4 (TBS) as a protein block, for $20 \mathrm{~min}$; the optimally diluted primary antibodies (p53 - Novocastra, 1:400; p16 ${ }^{\text {ink4 }}$ LabVision-Thermo, 1:400; EGFR - Ventana-Roche, 1:1; Ki67 - DAKO, 1:1; collagen XVII, clone: 9G2, 1:200 - proprietary [12], overnight (16 h); the post-primary reagent for $30 \mathrm{~min}$., and the NovoLink-peroxidase polymer peroxidase complex for $30 \mathrm{~min}$. Samples were washed after each incubation step $2 \times$ $5 \mathrm{~min}$ in TBS. Peroxidase activity was visualized using DAB/ $\mathrm{H}_{2} \mathrm{O}_{2}$ for 5-10 min under microscopic control. Finally, nuclear counterstaining was applied using hematoxylin-eosin. All incubations were performed in humidity chambers at room temperature. Immunostained slides were digitalized using a Pannoramic Scan instrument (3DHISTECH, Budapest, Hungary). The histological evaluation and the scoring of immunoreactions were done by three independent assessors using the Pannoramic Viewer software (Fig. 1.).

Table 1 Anatomical distribution of the analyzed tumors

\begin{tabular}{llrl}
\hline & Localization & No. & $\%$ \\
\hline Oral cavity & Tongue + sublingual region & 12 & $5.3 \%$ \\
Oropharynx & Soft Palate & 8 & $3.5 \%$ \\
& Oropharynx (other) & 23 & $10.2 \%$ \\
& Palatine tonsil & 21 & $9.2 \%$ \\
& Lingual tonsil & 12 & $5.3 \%$ \\
Hypopharynx & Tonsillo-lingual & 5 & $2.2 \%$ \\
& Total: & 69 & $30.6 \%$ \\
& & 43 & $19.0 \%$ \\
& Supraglottic & 42 & $18.5 \%$ \\
& Glottic & 43 & $19.0 \%$ \\
& Transglottic & 17 & $7.6 \%$ \\
& Total: & 102 & $45.1 \%$ \\
\hline
\end{tabular}




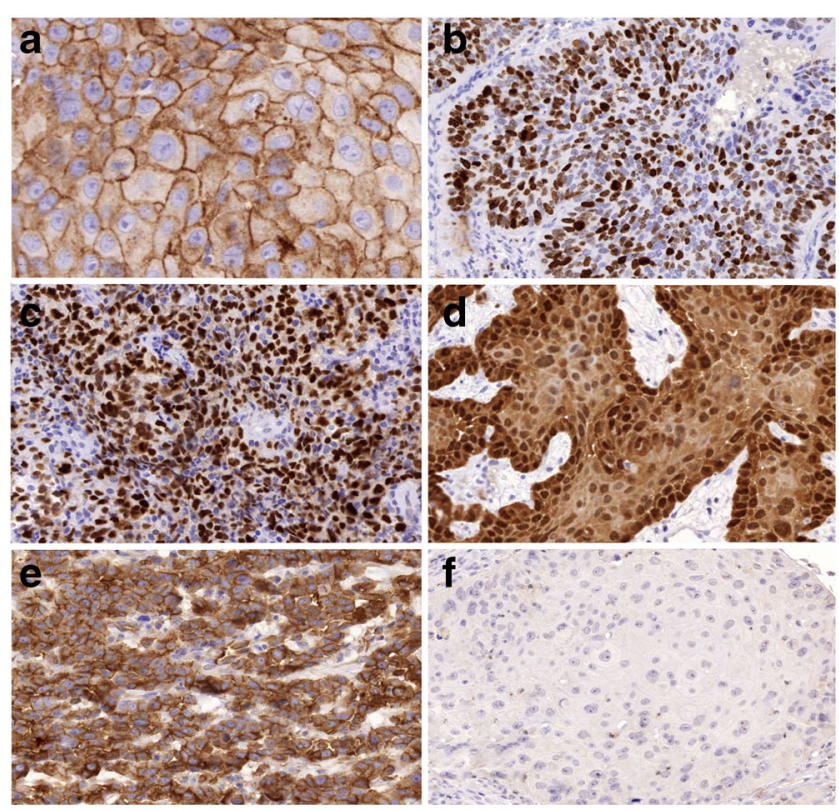

Fig. 1 Immunohistochemical staining: a: EGFR-positive oral cancer; $\mathbf{b}$ : Ki67-positive supraglottic cancer; c: p53-positive glottic cancer; d: p16 ${ }^{\text {ink } 4}$-positive tonsillar cancer; e: Coll.XVII-positive hypopharyngeal cancer; f: p16 ${ }^{\text {ink4 }}$-negative glottic cancer

Immunostained TMA spots were analyzed with the database-linked TMA Modul software (3DHISTECH). At least 3 tumor nests of $>200$ cells were considered for scoring in each sample. Scoring criteria were as follows: Score 0: $<5 \%$ weak staining; score $1:>5-25 \%$ positive tumor cells, score 2: $25-50 \%$ positive tumor cells; and score $3:>50 \%$ positive tumor cells. For statistical analysis scores were dichotomized along different thresholds. The most reproducible threshold for all assessors was set up when scores 0 and 1 were considered negative, while scores 2 and 3 as positive.
Statistical Analysis

Kaplan - Meier survival analyses were performed followed by Wilcoxon-Breslow tests for evaluating statistical difference in survival between groups The primary variables concerning survival were censored: patients with tumor-related death and patients having cancer at the time of last visit were considered dead, whereas tumor-free patients and those who died because of an intercurrent disease were considered alive.

Pearson's Chi-square tests were used for the analysis of the correlation between biomarker positivity and tumor localization.

Statistical analysis was carried out using the package of BMDP Statistical Software, Inc. (Los Angeles, California, USA), and significant difference was declared when the $p$ value was $<0.05$.

\section{Results}

Survival Analysis

We found statistically significant differences between survivals according to stage, the mean survival times were as follows: stage I - 112.9 months (Standard Error - S.E.: 13.481), stage II - 62.9 months (S.E.: 8.293), stage III 44.65 months (S.E.: 6.671) and stage IV - 22.76 months (S.E.: 2.531), $p=0.0000$ (Fig. 2.).

We also revealed significant differences between prognoses of diseases at different histological grade: grade I 96.30 months (S.E.: 11.352), grade II - 41.58 (S.E.: 4.252) and grade III -24.66 (S.E.: 4.546), $p=0.0001$ (Fig. 3.).
Fig. 2 Survivals according to tumor stage $(p=0.0000)$

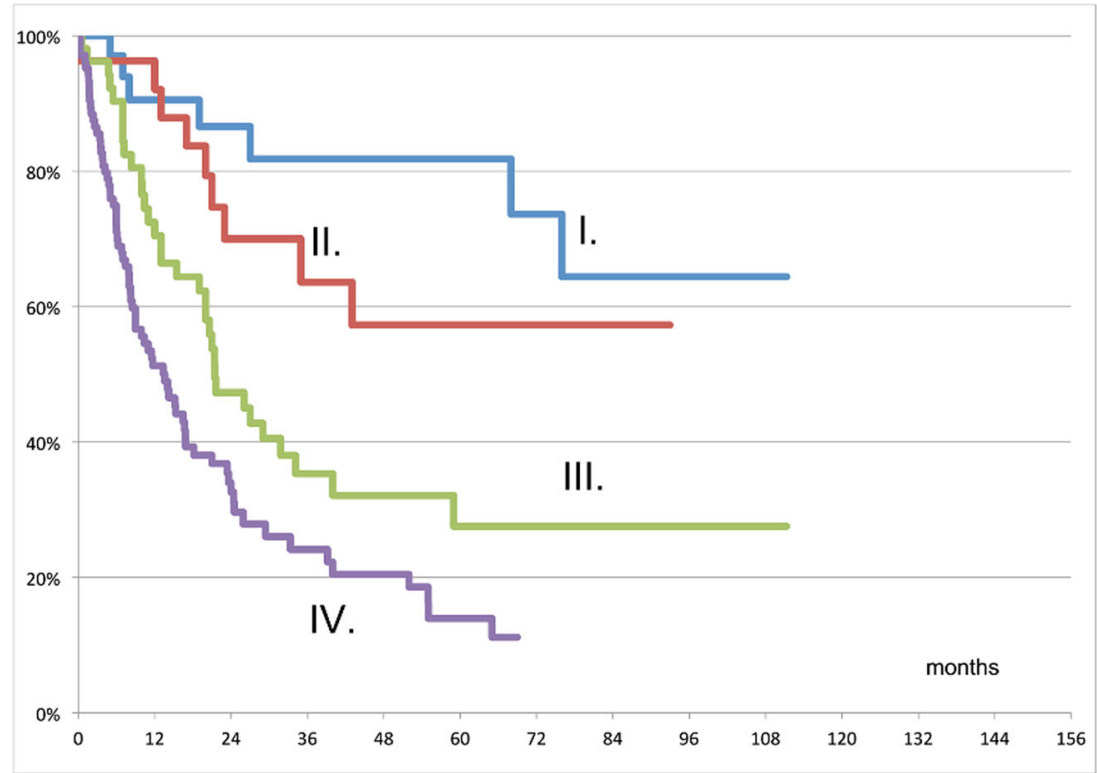


Fig. 3 Survivals according to histological grade $(p=0.0001)$

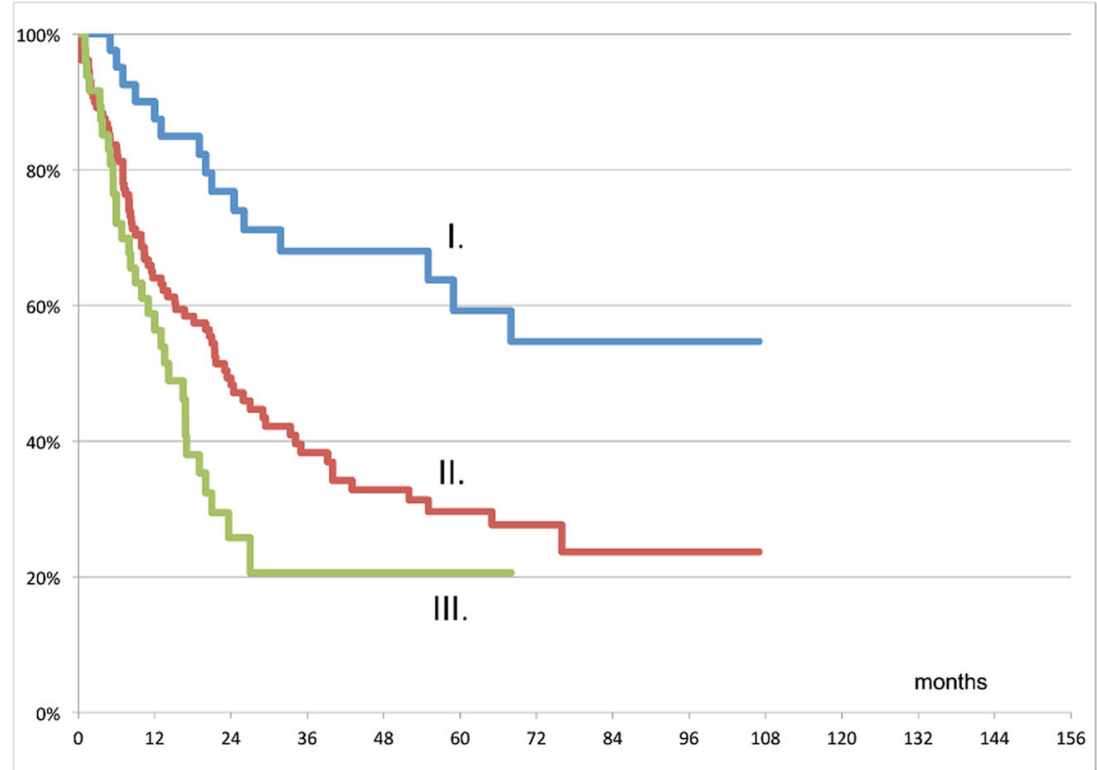

Comparing the patients'survivals according to the localizations of their malignancy, we found that patients with glottic cancers had the best (avg. survival time: 77.08 months S.E.: 7.211), and patients having hypopharyngeal tumors had the worst survival rates (avg. survival time: 20.37 months S.E.: 3.444), $p=0.0000$ (Fig. 4.).

From among the analyzed biomarkers, $\mathrm{p} 16^{\mathrm{ink} 4}$ and Ki67 correlated significantly with the prognosis. Patients with p $16^{\text {ink4 }}$-positive disease had higher survival rates than those with p16-negative cancer (median survival time: 55 vs. 20 months, $p=0.0049$ ) (Fig. 5.). Ki67-positivity correlated negatively to survival, patients with a Ki67-negative disease had better prognosis (median survival time: 20 vs. 27 months, $p=0.0243$ ) (Fig. 6.). Ki67-positivity was also associated with a higher nodal $(\mathrm{N})$ stage $(p=0.0067)$ (Table 2.).

Regarding the 43 patients having hypopharyngeal cancers, only 3 patients had Ki67-negative disease, and their mean survival was higher than those having Ki67-positive tumor (19.3 vs. 14 months).

As for the other biomarkers analyzed (EGFR, CollXVII, $\mathrm{p} 53$ ), there was no significant correlation either with survival, or with any clinical parameter.

Survival parameters by gender and age did not show significant differences ( $p=0.4210$ and 0.844 , respectively). In addition: there was no significant correlation between age and tumor stage or nodal status ( $p=0.528$ and 0.106 , respectively).
Fig. 4 Survivals according to tumor site $(p=0.0000)$

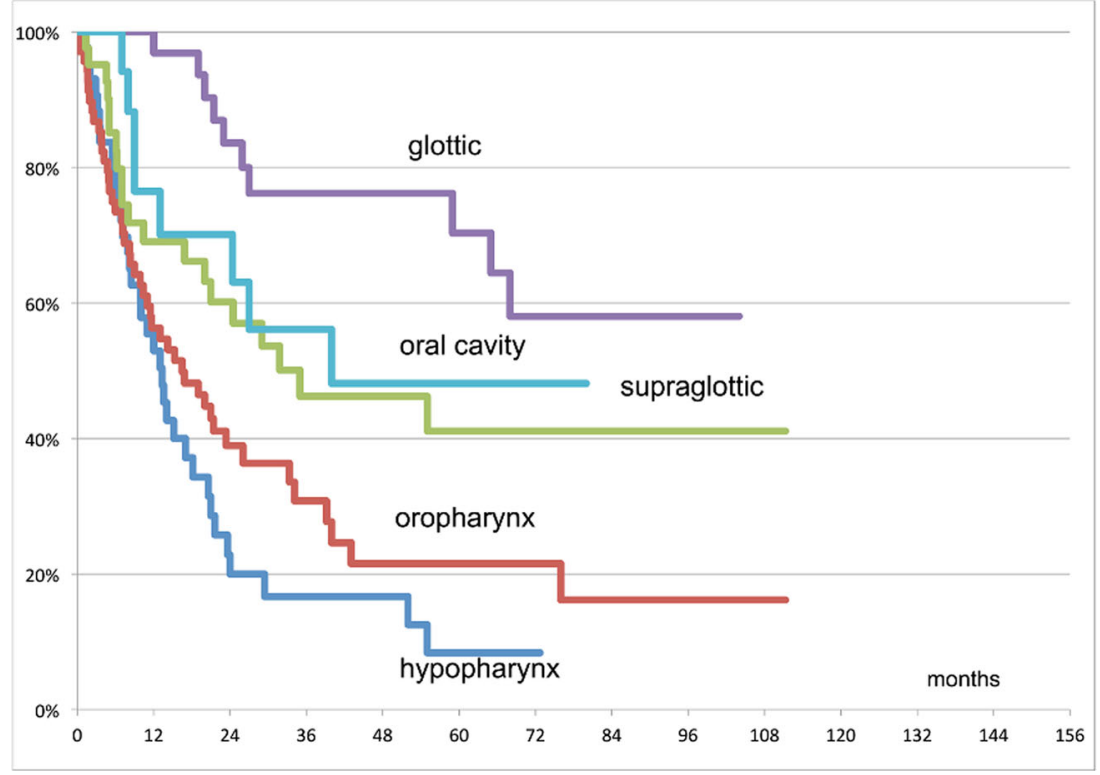


Fig. 5 Survivals according to p16 ${ }^{\text {ink4 }}$-positivity $(p=0.0049)$

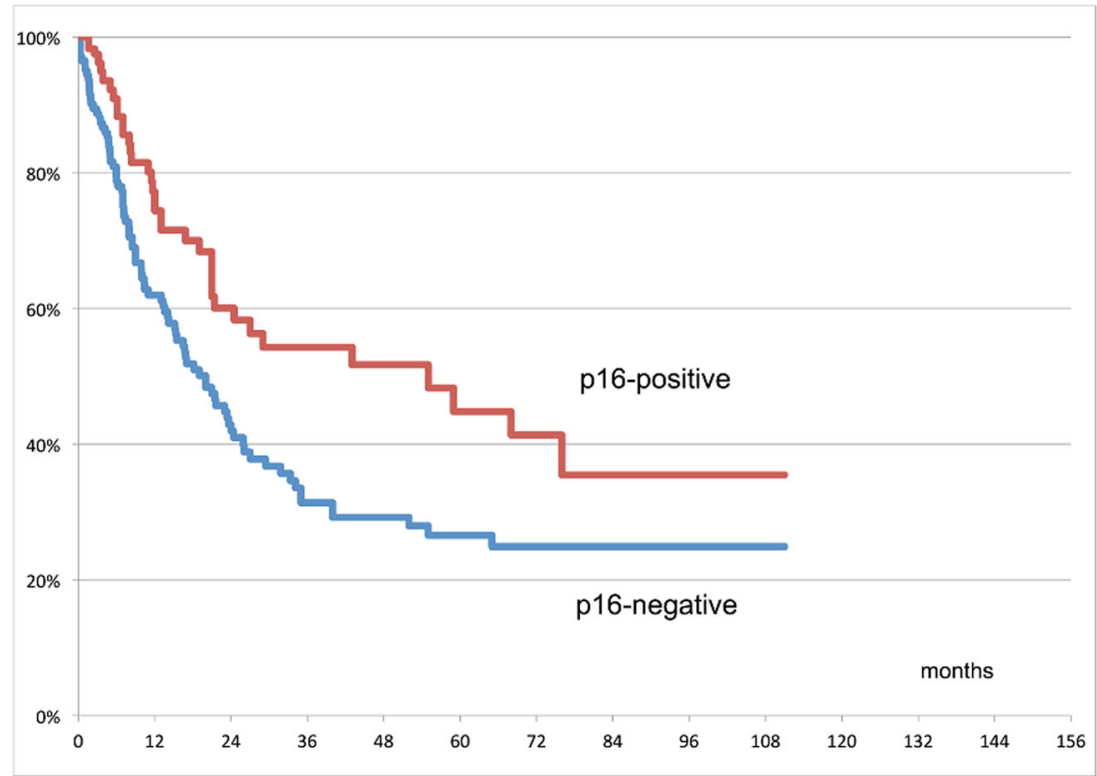

Then we compared the biomarker expressions according to a functional classification. This concept was mainly based on the distinct developmental routes followed by the subregions.

We took the tonsillar tumors (tumors of the palatine tonsil, tonsillo-lingual region, and base of the tongue,) together, and compared them to the other oropharyngeal and oral cancers, in order to compare the frequency of positive cases between these groups (Table 4). In this case, Ki67-positivity of the tonsillar group was significantly higher than that of the other oropharyngeal and oral tumors ( 84.2 vs. $60.0 \%, p=0.0406$ ).

The p $16^{\text {ink4 }}$-positivity of tonsillar tumors $(42.1 \%)$ was higher than that of the oral cavity + other oropharynx $(25.0 \%)$, but the difference was not significant ( $p=0.1976$ ).
Fig. 6 Survivals according to Ki67-positivity $(p=0.0243)$

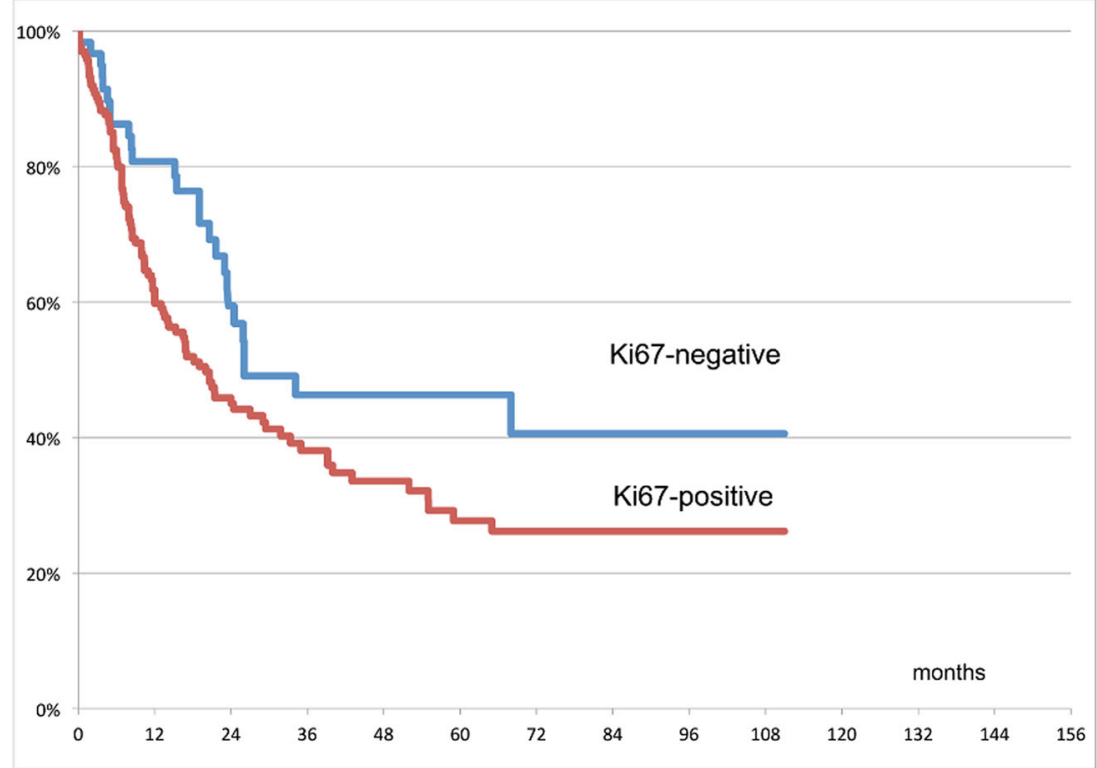


Table 2 Ki67-positivity ratio according to nodal $(\mathrm{N})$ stage $(p=0.0067)$

\begin{tabular}{lllll}
\hline & N0 & N1 & N2 & N3 \\
\hline Ki67-negative & $37.8 \%$ & $25 \%$ & $14.5 \%$ & $10 \%$ \\
Ki67-positive & $62.2 \%$ & $75 \%$ & $85.5 \%$ & $90 \%$
\end{tabular}

We did not reveal any significant differences in this arrangement regarding p53, EGFR and Collagen XVII expression.

Cancers of supraglottic area were also separated from those affecting other laryngeal regions (glottic and transglottic) (Table 5.). The ratio of Ki67 (85.4 vs. $50.8 \%, p=0.00037$ ) and EGFR (95.1 vs. $74.1 \%, p=0.0063$ ) positive tumors were significantly higher in the supraglottic group. The $\mathrm{p} 16^{\text {ink4 }}$ positivity of supraglottic tumors was also higher than the positivity of other laryngeal tumors, but this phenomenon did not reach the significancy level (52.5 vs. $33.3 \%, p=$ 0.056). Neither the p53-positive nor the Collagen XVII positive HNSCCs showed significant regional difference.

\section{Discussion}

In this study, our testing for potential prognostic biomarkers in HNSSC revealed that proliferating cell fractions significantly correlated with tumor prognosis. In particular, elevated number of Ki67 positive cells in hypopharyngeal cancers was in line with the worst prognostic outcome, while the lowest frequency of Ki67 positive cells in glottic cancers was associated with the best survival. Since, general proliferation markers as Ki67 may not detect cell fractions, which become arrested during the cell cycle, further studies using post-G1 phase and M-phase markers still needed to corroborate the prognostic role of proliferation in all subtypes of HNSSC.

Head and neck cancers cannot be regarded as a homogeneous entity, their clinical outcome can differ substantially according to their localization [2]. On one hand, this feature probably stems from the differing tissue constituents (membranes, ligaments, cartilages) surrounding the different head-
Table 4 Biomarker positivity ratio according to sub-localizations

\begin{tabular}{llllll}
\hline & $\begin{array}{l}\text { p16 } \\
\text { pos. }\end{array}$ & $\begin{array}{l}\text { Ki67 } \\
\text { pos. }\end{array}$ & $\begin{array}{l}\text { p53 } \\
\text { pos. }\end{array}$ & $\begin{array}{l}\text { Coll XVII } \\
\text { pos. }\end{array}$ & $\begin{array}{l}\text { EGFR } \\
\text { pos. }\end{array}$ \\
\hline $\begin{array}{l}\text { Tonsils } \\
\quad \text { (lingual + palatine) }\end{array}$ & $42.1 \%$ & $84.2 \%$ & $44.7 \%$ & $84.2 \%$ & $86.8 \%$ \\
$\begin{array}{c}n=38 \\
\text { Non-tonsillar } \\
\text { oropharynx }+ \\
\text { cavum oris } n=20\end{array}$ & $25 \%$ & $60 \%$ & $52.6 \%$ & $80 \%$ & $90 \%$ \\
$p$-value & 0.197 & 0.040 & 0.573 & 0.686 & 0.725 \\
\hline
\end{tabular}

neck mucosal regions that may restrict the migration, spread and lymphatic drainage of cancer cells [13].

Here, by using a larger patient cohort we confirmed our earlier finding on the differential expression of the biomarkers according to the anatomical regions within the head and neck area [11]. Besides its statistical links with sub-regional and prognostic features in HNSSC Ki67-positivity also showed significant positive correlation with poor survival in the whole patient cohort and was associated with higher nodal $(\mathrm{N})$ stage.

The TNM classification staging is perhaps the most important among clinical parameters that can predict the outcome of HNSCC [14]. TNM is simple, easy-to-use, and accepted worldwide. However, there can be significant inter-laboratory differences in the way TNM is used for HNSCC due to the varying diagnostic tools used. Another disadvantage of TNM categorization is that it does not take such important factors into consideration as co-morbidity, which would be useful for tumor staging [14]. In this study, we found significant inverse correlation between tumor stage and disease outcome, advanced disease was linked with poor survival.

Histological grading reflects tumor cell dedifferentiation. Several studies have suggested histological grade as a prognostic factor HNSCC; patients with high grade disease show poor survival rates [15]. Regarding the early-stage tongue cancers, however, not the grading, but the thickness of the lesion was of primary prognostic importance [16]. Here, we found significant inverse correlation between the histological grade of HNSCC and prognosis: patients with a grade I tumor had significantly better survival rates than those with grade III disease.
Table 3 Biomarker positivity ratio according to anatomical localizations

\begin{tabular}{|c|c|c|c|c|c|c|}
\hline & & p16 pos. & Ki67 pos. & p53 pos. & $\begin{array}{l}\text { Coll XVII } \\
\text { pos. }\end{array}$ & EGFR pos. \\
\hline \multicolumn{2}{|c|}{ Cavum oris $n=12$} & $25 \%$ & $58.3 \%$ & $50 \%$ & $91.7 \%$ & $100 \%$ \\
\hline \multicolumn{2}{|c|}{ Oropharynx $n=69$} & $36.2 \%$ & $75.4 \%$ & $48.5 \%$ & $73.5 \%$ & $78.3 \%$ \\
\hline \multicolumn{2}{|c|}{ Hypopharynx $n=43$} & $23.3 \%$ & $93 \%$ & $58.1 \%$ & $90.7 \%$ & $88.4 \%$ \\
\hline \multirow[t]{3}{*}{ Larynx $n=102$} & Supraglottic $n=42$ & $52.5 \%$ & $85.4 \%$ & $57.5 \%$ & $85.4 \%$ & $95.1 \%$ \\
\hline & Glottic $n=43$ & $34.9 \%$ & $40.5 \%$ & $54.8 \%$ & $81.4 \%$ & $73.2 \%$ \\
\hline & Transglottic $n=17$ & $29.4 \%$ & $76.5 \%$ & $46.7 \%$ & $70.6 \%$ & $76.5 \%$ \\
\hline \multicolumn{2}{|l|}{$p$-value } & 0.119 & 0.000 & 0.8937 & 0.170 & 0.0317 \\
\hline
\end{tabular}


Table 5 Biomarker positivity ratio according to sub-localizations

\begin{tabular}{llllll}
\hline & $\begin{array}{l}\text { p16 } \\
\text { pos. }\end{array}$ & $\begin{array}{l}\text { Ki67 } \\
\text { pos. }\end{array}$ & $\begin{array}{l}\text { p53 } \\
\text { pos. }\end{array}$ & $\begin{array}{l}\text { Coll XVII } \\
\text { pos. }\end{array}$ & $\begin{array}{l}\text { EGFR } \\
\text { pos. }\end{array}$ \\
\hline $\begin{array}{l}\text { Supraglottis } n=42 \\
\begin{array}{l}\text { Glottis + Transglottic } \\
n=60\end{array}\end{array}$ & $52.5 \%$ & $85.4 \%$ & $57.5 \%$ & $85.4 \%$ & $95.1 \%$ \\
$p$-value & 0.056 & $0.0003 \%$ & 0.635 & 0.374 & 0.0063 \\
\hline
\end{tabular}

p16 $6^{\text {ink4 }}$ inhibits cyclin dependent kinase (cdk) 4/6, which prevents the formation of the active cyclin D-cdk $4 / 6$ complex and early cell cycle progression. The lack of cyclin D mediated phosphorylation of the retinoblastoma $(\mathrm{Rb})$ protein results in the inactivation of the cell cycle in phase G1 [17]. Several reports suggest that reduced expression or the lack of p $16^{\text {ink } 4}$ protein correlates with poor prognosis of HNSCC [18, 19], which we confirmed in our tested patient cohort. Recent reports have revealed that $\mathrm{p} 16^{\text {ink4 }}$-expression is associated with HPV-positivity, implying that $\mathrm{p} 16^{\text {ink } 4}$ can be a surrogate marker for HPV detection.

Ki67 is a protein with unclarified functions, which can be detected in proliferating cells throughout the cell cycle (G1, S, $\mathrm{G} 2$ and $\mathrm{M}$ phases) but it is absent in resting (phase G0) cells. Therefore, Ki67 as a marker of tumor growth fraction, can carry important information about tumor agressiveness and therapeutic response [20-22]. Despite some groups could not confirm the prognostic role of Ki67 expression [23], in this study we found clear negative correlation between Ki67 positive cell fractions and overall survival and a positive link with higher nodal $(\mathrm{N})$ stage. Our results showing differential expression of Ki67 in hypopharyngeal (93.0 \%) compared to glottic $(40.5 \%)$ cancers are in line with the clinical observation, that patients with glottic cancers have better life expectancy and earlier symptoms than of those with hypopharyngeal cancers [24]. Ki67 index may also allow prospective prognostic stratification within the hypopharyngeal group since the $3 \mathrm{Ki} 67$ negative cases showed improved survival (19.3 vs. 14 months) compared to the Ki67 positive cases. This, however, needs further clarification in larger patient cohort. The frequency of Ki67-positive tumors was also significantly higher in the tonsillar group compared to the other oropharyngeal and oral malignancies.

Collagen XVII protein contributes to the hemidesmosomal adhesion of basal undifferentiated keratinocytes in stratified squamous epithelia [25]. In line with maturation, keratinocytes lose their collagen XVII expression, however, it can be detected as an early marker of malignant transformation in epidermal squamous cell carcinomas [26]. Apart from detecting collagen XVII in early in situ HNSCC, no significant difference in collagen XVII expression was noted in relation to any clinicopathological variable tested.
P53, known as the guardian of the genome, is one of the most commonly mutated tumor suppressor genes in human malignancies, thus, mutation of the p53 gene is common in head and neck cancers, too [27]. The prognostic role of p53 in head and neck cancers is controversial [28]. Some authors found negative correlation between p53 expression and prognosis [29], while others including this study could not prove this finding [30, 31].

Overexpression of epidermal growth factor receptor (EGFR) can be detected in more than $80-90 \%$ of HNSCC [32] either with or without gene amplification, and have been shown as a marker of poor prognosis [33, 34]. In our cohort, EGFR levels showed regional preference in HNSCC with the highest EGFR expression in oral cancers and the lowest in glottic cancers.

In conclusion, based on their biomarker expression profiles clinicopathologically relevant subgroups can be distinguished within the heterogeneous HNSCC group. The expression of Ki67 and EGFR show regional preference. Elevated Ki67positive cell fractions, reduced $\mathrm{p} 16^{\text {ink } 4}$ expression and high histological grade can be linked with poor prognosis of HNSC C. Therefore, supplementing conventional prognostic factors with a restricted biomarker profiling can assist in prognostic subtyping of HNSCC and may help designing a more efficient therapy.

Conflict of Interest Conflict of interest statement: We declare that we have no conflict of interest.

\section{References}

1. Parkin DM, Bray F, Ferlay J, Pisani P (2005) Global cancer statistics, 2002. CA Cancer J Clin 55(2):74-108

2. Jay F. Piccirillo IC, Marsha E. Reichman (2007) Chapter 2: Cancers of the Head and Neck. In: Ries LAG YJ, Keel GE, Eisner MP, Lin YD, Horner M-J (ed) SEER Survival Monograph: Cancer Survival Among Adults: U.S. SEER Program, 1988-2001, Patient and Tumor Characteristics. National Cancer Institute, SEER Program. NIH Pub No. 07-6215, Bethesda, MD

3. Vermorken JB, Mesia R, Rivera F, Remenar E, Kawecki A, Rottey S, Erfan J, Zabolotnyy D, Kienzer H-R, Cupissol D, Peyrade F, Benasso M, Vynnychenko I, De Raucourt D, Bokemeyer C, Schueler A, Amellal N, Hitt R (2008) Platinum-based chemotherapy plus cetuximab in head and neck cancer. N Engl J Med 359(11):11161127

4. Barzan L, Veronesi A, Caruso G, Serraino D, Magri D, Zagonel V, Tirelli U, Comoretto R, Monfardini S (1990) Head and neck cancer and ageing: a retrospective study in 438 patients. J Laryngol Otol 104(8):634-640

5. Massano J, Regateiro FS, Januario G, Ferreira A (2006) Oral squamous cell carcinoma: review of prognostic and predictive factors. Oral Surg Oral Med Oral Pathol Oral Radiol Endod 102(1):67-76

6. Ang KK, Sturgis EM (2012) Human papillomavirus as a marker of the natural history and response to therapy of head and neck squamous cell carcinoma. Semin Radiat Oncol 22(2):128-142. doi:10. 1016/j.semradonc.2011.12.004 
7. Franceschi S, Munoz N, Bosch XF, Snijders PJ, Walboomers JM (1996) Human papillomavirus and cancers of the upper aerodigestive tract: a review of epidemiological and experimental evidence. Cancer Epidemiol Biomarkers Prev 5(7):567-575

8. Ang KK, Harris J, Wheeler R, Weber R, Rosenthal DI, Nguyen-Tan $\mathrm{PF}$, Westra WH, Chung CH, Jordan RC, Lu C, Kim H, Axelrod R, Silverman CC, Redmond KP, Gillison ML (2010) Human papillomavirus and survival of patients with oropharyngeal cancer. N Engl $\mathrm{J}$ Med 363(1):24-35. doi:10.1056/NEJMoa0912217

9. Smeets SJ, Hesselink AT, Speel E-JM, Haesevoets A, Snijders PJF, Pawlita M, Meijer CJLM, Braakhuis BJM, Leemans CR, Brakenhoff RH (2007) A novel algorithm for reliable detection of human papillomavirus in paraffin embedded head and neck cancer specimen. Int $\mathrm{J}$ Cancer 121(11):2465-2472. doi:10.1002/ijc.22980

10. Licitra L, Storkel S, Kerr KM, Van Cutsem E, Pirker R, Hirsch FR, Vermorken JB, Von Heydebreck A, Esser R, Celik I, Ciardiello F (2013) Predictive value of epidermal growth factor receptor expression for first-line chemotherapy plus cetuximab in patients with head and neck and colorectal cancer: analysis of data from the EXTREME and CRYSTAL studies. Eur J Cancer 49(6):1161-1168

11. Tamas L, Szentkuti G, Eros M, Danos K, Brauswetter D, Szende B, Zsakovics I, Krenacs T (2011) Differential biomarker expression in head and neck cancer correlates with anatomical localization. Pathol Oncol Res 17(3):721-727

12. Krenacs T, Kiszner G, Stelkovics E, Balla P, Teleki I, Nemeth I, Varga E, Korom I, Barbai T, Plotar V, Timar J, Raso E (2012) Collagen $\mathrm{XVII}$ is expressed in malignant but not in benign melanocytic tumors and it can mediate antibody induced melanoma apoptosis. Histochem Cell Biol 138(4):653-667. doi:10.1007/s00418-012-0981-9

13. Repassy G, Czigner J, Ribari O, Lapis K (1988) The barrier-like role of activated connective tissue against the spread of supraglottic laryngeal carcinoma. Arch Oto-Rhino-Laryngol 245(3):151-154

14. van der Schroeff MP, Baatenburg de Jong RJ (2009) Staging and prognosis in head and neck cancer. Oral Oncol 45 (4-5):356-360. doi: http://dx.doi.org/10.1016/j.oraloncology.2008.05.022

15. Takes RP (2004) Staging of the neck in patients with head and neck squamous cell cancer: imaging techniques and biomarkers. Oral Oncol 40(7):656-667

16. O-charoenrat P, Pillai G, Patel S, Fisher C, Archer D, Eccles S, RhysEvans P (2003) Tumour thickness predicts cervical nodal metastases and survival in early oral tongue cancer. Oral Oncol 39(4):386-390

17. Nilsson K, Svensson S, Landberg G (2004) Retinoblastoma protein function and p16INK4a expression in actinic keratosis, squamous cell carcinoma in situ and invasive squamous cell carcinoma of the skin and links between p16INK4a expression and infiltrative behavior. Mod Pathol 17(12):1464-1474

18. Ai LB, Stephenson KK, Ling WH, Zuo CL, Mukunyadzi P, Suen JY, Hanna E, Fan CY (2003) The p16 (CDKN2a/INK4a) tumorsuppressor gene in head and neck squamous cell carcinoma: A promoter methylation and protein expression study in 100 cases. Mod Pathol 16(9):944-950. doi:10.1097/01.mp.0000085760.74313.dd

19. Weinberger PM, Yu Z, Haffty BG, Kowalski D, Harigopal M, Sasaki C, Rimm DL, Psyrri A (2004) Prognostic significance of $\mathrm{p} 16$ protein levels in oropharyngeal squamous cell cancer. Clin Cancer Res 10(17):5684-5691. doi:10.1158/1078-0432.ccr-04-0448

20. Cattoretti G, Becker MH, Key G, Duchrow M, Schluter C, Galle J, Gerdes J (1992) Monoclonal antibodies against recombinant parts of the Ki-67 antigen (MIB 1 and MIB 3) detect proliferating cells in microwave-processed formalin-fixed paraffin sections. J Pathol 168(4):357-363
21. Matsumoto M, Komiyama K, Okaue M, Shimoyama Y, Iwakami K, Namaki S, Tanaka H, Moro I, Sato H (1999) Predicting tumor metastasis in patients with oral cancer by means of the proliferation marker Ki67. J Oral Sci 41(2):53-56

22. Sittel C, Eckel HE, Damm M, von Pritzbuer E, Kvasnicka HM (2000) Ki-67 (MIB1), p53, and Lewis-X (LeuM1) as prognostic factors of recurrence in $\mathrm{T} 1$ and $\mathrm{T} 2$ laryngeal carcinoma. Laryngoscope 110(6):1012-1017. doi:10.1097/00005537200006000-00024

23. Roland NJ, Caslin AW, Bowie GL, Jones AS (1994) Has the cellular proliferation marker ki67 any clinical relevance in squamous cell carcinoma of the head and neck? Clin Otolaryngol Allied Sci 19(1): 13-18. doi:10.1111/j.1365-2273.1994.tb01140.x

24. Berrino F, Gatta G (1998) Variation in survival of patients with head and neck cancer in Europe by the site of origin of the tumours. EUROCARE Working Group. Eur J Cancer 34(14 Spec No):2154 2161

25. Franzke C-W, Bruckner P, Bruckner-Tuderman L (2005) Collagenous transmembrane proteins: recent insights into biology and pathology. J Biol Chem 280(6):4005-4008

26. Stelkovics E, Korom I, Marczinovits I, Molnar J, Rasky K, Raso E, Ficsor L, Molnar B, Kopper L, Krenacs T (2008) Collagen XVII/BP180 protein expression in squamous cell carcinoma of the skin detected with novel monoclonal antibodies in archived tissues using tissue microarrays and digital microscopy. Appl Immunohistochem Mol Morphol 16(5):433-441

27. Somers KD, Merrick MA, Lopez ME, Incognito LS, Schechter GL, Casey G (1992) Frequent p53 mutations in head and neck cancer. Cancer Res 52(21):5997-6000

28. Tandon S, Tudur-Smith C, Riley RD, Boyd MT, Jones TM (2010) A systematic review of $\mathrm{p} 53$ as a prognostic factor of survival in squamous cell carcinoma of the four main anatomical subsites of the head and neck. Cancer Epidemiol Biomarkers Prev 19(2):574587

29. Bradford CR, Zhu S, Ogawa H, Ogawa T, Ubell M, Narayan A, Johnson G, Wolf GT, Fisher SG, Carey TE (2003) p53 mutation correlates with cisplatin sensitivity in head and neck squamous cell carcinoma lines. Head Neck 25(8):654-661

30. Perisanidis C, Perisanidis B, Wrba F, Brandstetter A, El Gazzar S, Papadogeorgakis N, Seemann R, Ewers R, Kyzas PA, Filipits M (2012) Evaluation of immunohistochemical expression of p53, p21, p27, cyclin D1, and Ki67 in oral and oropharyngeal squamous cell carcinoma. J Oral Pathol Med 41(1):40-46

31. Tamas L, Kraxner H, Mechtler L, Repassy G, Ribari O, Hirschberg A, Szentkuti G, Jaray B, Szentirmay Z (2000) Prognostic significance of P53 histochemistry and DNA histogram parameters in head and neck malignancies. Anticancer Res 20(5 C):4031-4038

32. Grandis JR, Tweardy DJ (1993) Elevated levels of transforming growth factor $\alpha$ and epidermal growth factor receptor messenger RNA are early markers of carcinogenesis in head and neck cancer. Cancer Res 53(15):3579-3584

33. Grandis JR, Melhem MF, Gooding WE, Day R, Holst VA, Wagener MM, Drenning SD, Tweardy DJ (1998) Levels of TGF- $\alpha$ and EGFR protein in head and neck squamous cell carcinoma and patient survival. J Natl Cancer Inst 90(11):824-832

34. Szabo B, Nelhubel GA, Karpati A, Kenessey I, Jori B, Szekely C, Petak I, Lotz G, Hegedus Z, Hegedus B, Fule T, Dome B, Timar J, Tovari J (2011) Clinical significance of genetic alterations and expression of epidermal growth factor receptor (EGFR) in head and neck squamous cell carcinomas. Oral Oncol 47(6):487-496 